\title{
Managing infective endocarditis in the elderly: new issues for an old disease
}

This article was published in the following Dove Press journal:

Clinical Interventions in Aging

2 September 2016

Number of times this article has been viewed

\section{Emmanuel Forestier' \\ Thibaut Fraisse ${ }^{2}$ \\ Claire Roubaud-Baudron ${ }^{3}$ \\ Christine Selton-Suty ${ }^{4}$ \\ Leonardo Pagani ${ }^{5}$}

'Infectious Diseases Department, Centre Hospitalier Métropole Savoie, Chambéry, France; ${ }^{2}$ Acute Geriatric Department, Centre Hospitalier, Alès, France; ${ }^{3}$ Geriatric Department, University Hospital, Bordeaux, France; ${ }^{4}$ Department of Cardiology, University Hospital, Nancy, France; Infectious

Diseases Department, Centre Hospitalier Annecy-Genevois, Annecy, France
Correspondence: Emmanuel Forestier Service de maladies infectieuses, Centre Hospitalier Métropole Savoie, BP I I25, 730II Chambery Cedex, France

Tel +33479965847

Fax +3347996 5I7I

Email emmanuel.forestier@ch-metropolesavoie.fr

\begin{abstract}
The incidence of infective endocarditis (IE) rises in industrialized countries. Older people are more affected by this severe disease, notably because of the increasing number of invasive procedures and intracardiac devices implanted in these patients. Peculiar clinical and echocardiographic features, microorganisms involved, and prognosis of IE in elderly have been underlined in several studies. Additionally, elderly population appears quite heterogeneous, from healthy people without past medical history to patients with multiple diseases or who are even bedridden. However, the management of IE in this population has been poorly explored, and international guidelines do not recommend adapting the therapeutic strategy to the patient's functional status and comorbidities. Yet, if IE should be treated according to current recommendations in the healthiest patients, concerns may rise for older patients who suffer from several chronic diseases, especially renal failure, and are on polypharmacy. Treating frailest patients with high-dose intravenous antibiotics during a prolonged hospital stay as recommended for younger patients could also expose them to functional decline and toxic effect. Likewise, the place of surgery according to the aging characteristics of each patient is unclear. The aim of this article is to review the recent data on epidemiology of IE and its peculiarities in the elderly. Then, its management and various therapeutic approaches that can be considered according to and beyond guidelines depending on patient comorbidities and frailty are discussed.
\end{abstract}

Keywords: infective endocarditis, elderly, antibiotic therapy, cardiac surgery, frailty

\section{Introduction}

Infective endocarditis (IE) is a rare but severe disease that increasingly involves older patients: more than one-third is indeed over 70 years old in Western countries nowadays. ${ }^{1,2}$ In this patient setting, IE displays several peculiarities, as predisposing cardiac conditions, clinical and echocardiographic features, and microorganisms involved. The mortality also tends to be higher than in the general population. ${ }^{3-6} \mathrm{Nev}-$ ertheless, age itself is not a good surrogate marker to define a unique population. Aging is a heterogeneous process resulting in a wide spectrum of aged people profiles, from perfectly healthy to bedridden ones. So, in case of infection, a comprehensive geriatric assessment (nutritional, functional, and cognitive) is certainly necessary to evaluate and predict outcome, but also to guide treatment. ${ }^{7}$ However, none of the international guidelines tackles the management of IE in the elderly, and to what extent they can be applied to these patients remains poorly evaluated..$^{8-11}$ Yet, if healthiest elderly suffering from IE should be managed according to such recommendations, therapeutic strategy certainly requires adaptation in frail patients.

The aim of this article is to review the recent data on epidemiology of IE and its peculiarities in the elderly. Its management and various therapeutic approaches according to patient comorbidities and frailty are also discussed. It is not intended as 
a systematic review or a meta-analysis, but a summary of the most recent acquisitions about an emerging clinical concern for elders. Therefore, we performed a search in PubMed for terms such as "infective endocarditis," "infective endocarditis AND aged," "endocarditis AND geriatric," "endocarditis treatment." Then the authors selected the most relevant papers (in their opinion) focusing on this peculiar disease in the geriatric setting (over 65 years), aiming at summarizing the present advances, unmet needs, and potential solutions.

\section{Recent epidemiological trends Patients involved}

The incidence of IE in the general population has slightly increased since the $1980 \mathrm{~s}$ in industrialized countries. The incidence of IE was close to 20 in a study performed in France in 1991, whereas it is now estimated around 30-90 per million inhabitants. $^{12,13}$ Overall, males are mostly involved with a sex-ratio exceeding 2:1. ${ }^{13}$ Concordant epidemiological studies showed that the rising incidence of IE mostly occurred in elderly population. ${ }^{1,2,14}$ Mean age of patients increased from 45.3 years in 1980 s to 57.2 years in 2000 s, according to a literature review. ${ }^{2}$ Moreover, in a large French observational study performed in 2008, patients aged 70 or older represented $38.7 \%$ of cases of IE, and the peak of incidence for male patients was between 75 and 79 years, reaching 194 cases per million of inhabitants. ${ }^{1}$ This trend is first explained by aging of the general population. Age-related degenerative valvular damages are now the most frequently involved underlying heart lesions. ${ }^{6}$ The increasing number of cardiovascular electronic devices, prosthetic valves implants, transcatheter aortic valve implantation (TAVI), along with frequent invasive diagnostic or therapeutic procedures performed in elderly, may also contribute to the rise of IE in this population and especially of health care-associated (HA) IE. Indeed, in a large international cohort of IE prospectively followed up in the early 2000s, more than half of elderly patients reported invasive procedures in the 6 months preceding the occurrence of IE. ${ }^{6}$ In another study, HA IE accounted for $34 \%$ of the cases, and in the study by Selton-Suty et al, the increased incidence of IE in older patients was mostly attributable to HA IE. ${ }^{1,15}$

\section{Microorganisms responsible for IE}

Although oral streptococci were previously responsible for most cases of IE in elderly, recent studies demonstrated that staphylococci are now mainly involved, Staphylococcus aureus being predominant. ${ }^{1,2,14,16}$ Methicillin-resistant S. aureus is often found in older patients. ${ }^{6}$ This epidemiological trend is likely linked to the increasing incidence of HA IE.
On the other hand, the frequency of IE caused by streptococci colonizing the digestive tract like Streptococcus gallolyticus and enterococci also increases because of the higher incidence of colonic lesions in elderly patients. Conversely, IE due to other microorganisms, such as Enterobacteriaceae and fungi, or negative blood culture IE remain rare. ${ }^{1,4,6,15}$

\section{Peculiarities of IE in the elderly}

Main data on predisposing conditions, clinical presentation, echocardiographic data, surgical and medical treatment, and morbidity and mortality are globally concordant across studies on IE in elderly. ${ }^{3-6,17-20}$ However, these results are sometimes contradictory to some extent, due to differences in methods and the heterogeneous definition of elderly patients that ranged from over 64 to over 75 years.

IE occurs mainly in older patients suffering from multiple comorbidities. Diabetes, gastrointestinal or genitourinary cancer, or multiple chronic illnesses are found in more than half of elderly patients with IE. ${ }^{5,6}$ The presumed portal of entry of the pathogen is indeed more frequently the digestive or urinary tract. Mitral regurgitation, nonrheumatic aortic stenosis, prosthetic valve, and intracardiac devices are the most frequent conditions predisposing to IE in this population: among IE patients $\geq 65$-years old included in a large international cohort study, almost $20 \%$ had a pacemaker or an automatic implantable defibrillator. ${ }^{1,6}$ A concern has also recently emerged with IE complicating TAVI. ${ }^{21,22}$ Its incidence was $0.7 \%$ among patients implanted in a recent retrospective study in North America, $75 \%$ of IE occurring within the year following the procedure. ${ }^{21}$ The two risk factors for IE found in this study were orotracheal intubation and the use of a self-expandable CoreValve system.

Clinical presentation of IE in elderly is often nonspecific, consisting in general symptoms such as fatigue, weight loss, or confusion. Fever seems to be as common as in younger patients and time between onset of symptoms and diagnosis was rather shorter in patients over 75 years in Remadi et al's study. ${ }^{5}$ Immunological events (Osler nodules, Roth spots, and Janeway lesions) and embolic complications such as strokes, intracranial hemorrhages, or mycotic aneurysms are likely less frequent. ${ }^{6}$ This observation should nevertheless be considered with caution since these last complications could be less systematically assessed in elderly.

Echocardiographic data also exhibit some specificity: mitral valve is more frequently affected, vegetations and valve defects are less frequent, whereas peri-valvular abscesses are more often found., ${ }^{4,6}$ Transesophageal echocardiography could therefore lead to a significant diagnostic gain 
in older patients. However, cooperation of elderly patients for transesophageal echocardiography may be difficult because of cognitive disorder or agitation. Resorting to sedation or general anesthesia is also risky when patients have polymedication or multiple comorbidities.

The impact of IE on functional status in elderly has not been studied to date. Only one study has shown that age $\geq 60$ years was associated with a decreased quality of life 12 months after IE. ${ }^{23}$ Lethality tends to be higher than in the general population: it ranges from $16 \%$ to $45 \%$ in patients aged 65 years or older. It could be even higher in case of IE following TAVI, reaching $66 \%$ at 1 -year follow-up, including $47 \%$ of in-hospital mortality, in Amat-Santos et al's study. ${ }^{21}$ Age appears as a major risk factor for death regardless of concomitant comorbidities. ${ }^{1,3-6,18,20}$ There is no clear explanation to this observation. Thorough geriatric assessment was never performed in IE studies. Therefore, the influence of functional and socioeconomic status on IE management (medical or surgical) and attributable morbidity or mortality could not be evaluated. Elderly patients might die from worsening concomitant comorbidities. They may also experience more complications from the medical and surgical management. Conversely, other studies showed that elderly patients undergo heart surgery less frequently than younger patients, which could constitute a loss of chance..$^{3-6}$

\section{Management of IE in the elderly Considering aging issues}

Aging is a heterogeneous process that leads to a wide variety of patient profiles ranging from healthy aging (without any comorbidity or disability) to bedridden patients. In between there is a continuum from frail patients with comorbidities and altered functional, nutritional, and cognitive statuses. Frailty is defined as a wasting syndrome accompanied by increased vulnerability to functional disability, morbidity, and mortality. It is a transitional state that should be recognized to prevent or treat the trigger event that will in turn precipitate functional decline of a single organ or global functional status. ${ }^{24}$ Considering frailty becomes essential to determine in which category of aging phenotype an elderly patient could be classified, to evaluate his/her physiological reserve, and then to assess suitability for intensive medical or surgical procedures, such as TAVI. ${ }^{25}$ Likewise, the well know Fried criteria assessing frailty (involuntary weight loss, weakness, self-reported exhaustion, low physical activity, or slow walking speed) were recently evaluated for therapeutic decision-making regarding renal replacement in elderly patients with advanced chronic kidney disease. ${ }^{26,27}$
Assessing frailty also seems crucial to guide treatment in severe infectious diseases, such as IE. Yet, no studies have evaluated the functional status as a risk factor and an outcome measure in this field. ${ }^{7}$ The recent guidelines on IE indicate that the treatment must be based on a medical and surgical approach in most cases, but there is no recommendation dedicated to elderly. ${ }^{8-11}$ Although patients who had a healthy aging should be managed according to these guidelines as do younger patients, others, from frail to bedridden ones, probably deserve an adapted care. For example, among the several options available for antibiotic therapy of IE, some may be preferred to others in patients with multiple comorbidities for the lower likelihood of toxicity or side effects. Alternative therapeutic strategies might also be considered in those patients, as the objectives would be not only treatment efficacy but also prevention of untoward effects. Regarding surgery, European guidelines ${ }^{10}$ recommend assessing the operative risk using several scores and considering the patient's comorbidities and clinical status, but they do not provide any specific tools. Since recommendations do not answer all the issues encountered when managing IE in elderly, the goal of this section is to provide suggestions to help clinicians adapt the medical and surgical treatment according to patient aging profile. Table 1 summarizes these proposals.

\section{Antibiotic therapy}

According to the European Society of Cardiology ${ }^{10}$ and American Heart Association, ${ }^{11}$ antibiotic therapy of IE relies on monotherapy or combination (as appropriate) of bactericidal drugs active on the microorganism involved, administered intravenously, at high dosage and for up to 6 weeks. The objective is to eradicate the slow growing bacteria present in vegetations and biofilm that exhibit tolerance to most antibiotics. Conversely, aging is associated with various physiologic changes corresponding to aging of each organ and induces pharmacokinetic modifications. ${ }^{28}$ The most important modifications for antibiotic pharmacokinetics in elders are fat mass increase, nephronic loss, and albumin level modification. The modification of fat mass level that increases with age modifies the volume of distribution of antibiotic according to their lipophilic or hydrophilic properties. Decreased albumin level may impair transport of highly protein-bound drugs and therefore the drug-free fraction.

Elderly patients have also a lower renal clearance, as renal function progressively decreases with age. This will lead to an increased risk of nephrotoxicity or systemic adverse events when choosing renally cleared antimicrobials without dosing adjustment. Clinicians should be aware that 
Table I Adaptation and alternatives to 2015 guidelines on IE suggested according to elder's comorbidities and functional status ${ }^{10,11}$

\begin{tabular}{|c|c|c|}
\hline & Guidelines & Suggested in elderly \\
\hline Transesophageal echography & $\begin{array}{l}\text { In all cases except negative TTE and low clinical } \\
\text { suspicion }\end{array}$ & $\begin{array}{l}\text { In case of major confusion and agitation exposing to excess } \\
\text { risk of the procedure, consider only repeated TTE in patients } \\
\text { contraindicated to surgery }\end{array}$ \\
\hline Aminoglycosides & $\begin{array}{l}\text { Combined to penicillin A or G or vancomycin } \\
\text { in case of streptococcal or enterococcal or } \\
\text { staphylococcal endocarditis as stated }\end{array}$ & $\begin{array}{l}\text { Consider aminoglycoside free regimens to avoid renal } \\
\text { toxicity }\end{array}$ \\
\hline Vancomycin & $\begin{array}{l}\text { First-line therapy in } \beta \text {-lactam allergic patients } \\
\text { or in case of MRSA }\end{array}$ & Consider daptomycin to avoid renal toxicity \\
\hline Therapeutic drug monitoring & Only for vancomycin and aminoglycosides & $\begin{array}{l}\text { Consider also for all } \beta \text {-lactams to avoid overdose and } \\
\text { underdose adverse effects (neurological toxicity) and } \\
\text { inefficacy, respectively }\end{array}$ \\
\hline Intravenous therapy & Throughout the antibiotic therapy in all cases & $\begin{array}{l}\text { Consider oral or subcutaneous route for antibiotic therapy if } \\
\text { infection is under control and in case of poor venous access } \\
\text { and/or agitation }\end{array}$ \\
\hline Outpatient parenteral therapy & $\begin{array}{l}\text { Only in reliable and compliant patients living } \\
\text { close to the hospital }\end{array}$ & $\begin{array}{l}\text { Consider in patients for whom the hospital stay is the most } \\
\text { deleterious regarding their functional and cognitive decline, } \\
\text { especially for elderly living in long-term care facilities }\end{array}$ \\
\hline
\end{tabular}

Note: Data from Habib et al ${ }^{10}$ and Baddour et al."

Abbreviations: IE, infective endocarditis; MRSA, methicillin-resistant Staphylococcus aureus; TTE, Trans-thoracic echocardiography.

elderly patients suffering from diabetes, or using diuretics and ACE inhibitors, are more prone to develop acute kidney injury caused by nephrotoxic drugs, such as aminoglycosides or vancomycin. ${ }^{28,29}$ Physiologic changes occurring with aging could modify antibiotic pharmacokinetics by themselves and favor overdose, leading for example to neurotoxic effect in patients with cognitive disorders. ${ }^{28}$ Conversely, an excess of precaution may induce an underdosing and a decreased efficacy. Given their bactericidal activity and safety, penicillins are the antibiotics of choice against susceptible strains of staphylococci and streptococci. Higher dosages are necessary, and dosing interval should be reduced to 4 hours to target stable serum concentration above minimal inhibitory concentration (MIC) over 24 hours. ${ }^{30}$ Continuous infusion may also be advantageous but remains to be validated. ${ }^{31}$ In case of methicillin-resistant $S$. aureus or in patients allergic to $\beta$-lactams, vancomycin is universally accepted as the first-line drug. It can be administered by intermittent or continuous infusion, which was proven to be effective and less toxic. ${ }^{32}$ Teicoplanin, recommended only by the British Society for Antimicrobial Chemotherapy guidelines, could also be considered, as it has a lower renal toxicodynamic profile than vancomycin and a very long half-life, allowing once-daily injection or even a thrice-weekly administration; it is slightly more active than vancomycin against enterococci as well. ${ }^{9,33}$ Daptomycin, a rapidly bactericidal cyclic lipopeptide, has been validated to treat right-sided staphylococcal endocarditis and seems to be well tolerated in the elderly population. ${ }^{34,35} \mathrm{It}$ is much more expensive than vancomycin, but it could be considered the drug of choice in patients with severely impaired renal function, and in case of IE affecting cardiac implantable electronic devices for its proven activity against bacterial biofilm. ${ }^{9-11,13}$

Combination antimicrobial treatment may facilitate bacterial clearance. Rifampin in combination with penicillin or vancomycin is strongly recommended in cases of staphylococcal prosthetic valve endocarditis or intravascular device infection. ${ }^{8-11}$ But several drug-drug interactions and frequent digestive side effects complicate its use in patients under polypharmacy. The interest of aminoglycosides is increasingly debated, especially for older patients, despite their rapid and strong bactericidal activity. A recent metaanalysis showed no benefit from combination therapy with aminoglycosides compared to $\beta$-lactam monotherapy for treating IE, while renal function declined more likely with the former regimen. ${ }^{36}$ In patients over 75 years, aminoglycosides treatment longer than 3 days is associated with increased nephrotoxicity. ${ }^{29}$ Thus, the synergistic interaction of aminoglycosides with $\beta$-lactams might be relevant in elderly only in cases of staphylococcal prosthetic valve endocarditis. In case of enterococcal endocarditis, amoxicillin could be combined to ceftriaxone rather than to gentamycin, especially in elderly patients at risk of or with renal impairment. This regimen is recommended in the 2015 guidelines $^{10,11}$ as in two studies that included mainly old patients, it appeared effective and safe, and much less toxic than aminoglycoside-containing regimens. ${ }^{10,11,37,38}$ Likewise, one single daily aminoglycoside administration should now be preferred according to the last European guidelines, since it is associated with lower nephrotoxicity than split injections. ${ }^{10}$ This is especially true in elderly with or at risk of impaired renal function..$^{39-42}$ Monitoring drug serum concentrations to attain therapeutic 
levels and avoid overdose or underdose could be useful. It is especially mandatory to manage efficacy of aminoglycosides (peak concentration) and prevent toxicity of aminoglycosides and glycopeptides (trough concentration). ${ }^{42,43}$

Functional decline is one of the most important risks arising from a prolonged hospitalization in elderly patients, particularly in those with cognitive disorders. Outpatient parenteral antibiotic therapy can limit this risk allowing early discharge of patients, and it appears safe and cost-effective, provided that it is performed in optimal conditions. ${ }^{44-48}$ According to guidelines, it could be considered after 1 week of antibiotic therapy in streptococcal endocarditis and after 2 weeks in other cases. Infection has to be under control, and the patient must not experience heart failure, neurological signs, renal impairment, surgical indication, or concerns about echocardiographic findings. ${ }^{9-11,49}$ A careful evaluation of the patient's social environment is important for supervision of treatment and complications of IE. Once or twice daily antibiotic regimens (ceftriaxone, teicoplanin, or daptomycin) should be preferred, but continuous cloxacillin or vancomycin could also be used. Venous access should be discussed before discharge from hospital (peripherally inserted central catheter [PICC], peripheral catheter, or direct intravenous injection), and close monitoring of patients should be organized along the whole ambulatory treatment.

Although intravenous route is the only recommended method to administer antibiotics for IE, maintaining a venous access for weeks could be a major concern in elderly. Cognitive disorders or confusion associated with agitation could compromise intravenous device retention. Long-term intravascular devices such as PICC can be complicated with thrombosis or superinfection. Thus, hypodermoclysis, which was developed to give fluid replacement or drug to geriatric patients, may be an alternative. ${ }^{50-52}$ This practice appears common among French infectious disease physicians and geriatricians, whereas there are only few data on subcutaneous administration of antibiotics. ${ }^{53}$ Ceftriaxone is the most used antibiotic for subcutaneous injection in France and appears really interesting to treat streptococcal native valve IE. However, very few pharmacokinetic and clinical data are available until now. ${ }^{54-57}$ Teicoplanin has also been used subcutaneously with very scarce published data. ${ }^{58,59}$ Conversely, aminoglycosides are sometimes used via subcutaneous route, but we do not recommend this for the important risk of skin necrosis and lack of efficacy. ${ }^{29,53,60-62}$ An oral antibiotic regimen might also be considered after initial intravenous therapy. Antibiotic must then have a good bioavailability (absorption) and diffusion, as do fluoroquinolones plus rifampin, or more recent drugs such as linezolid. However, this strategy relies on only a few observational and small-sized studies and thus remains to be validated. ${ }^{63}$

\section{Surgical treatment}

Surgery is often necessary in addition to antibiotic therapy to treat IE, either in case of severe valvular damage responsible for heart failure, extended vegetation at risk of systemic embolism, or uncontrolled infection. ${ }^{10,11}$ It is considered mandatory for prosthetic valve endocarditis, especially caused by $S$. aureus. Likewise, removing an infected intravascular device is strongly recommended. Nevertheless, surgery could be rarely performed in case of IE complicating TAVI, a procedure used as an alternative to open heart surgery in disabled elderly. ${ }^{21,22}$ Timing of surgery is still a matter of debate. ${ }^{64}$ Besides the cases of life-threatening complications, which make valvular surgery emergent, whether it should be performed early in the course of the disease or delayed should be discussed case-by-case. ${ }^{9-11}$

Age per se is not a contraindication to surgery. One study showed that elderly could benefit from surgery with mortality reaching $61 \%$ in case of medical treatment alone compared with $39 \%$ for patients who underwent surgery. ${ }^{6}$ These results must be interpreted with caution since the operated patients probably had better baseline conditions. However, surgery should be systematically discussed for each patient: a careful multidisciplinary evaluation is essential to evaluate the benefit and the risk of the procedure. Several scores were developed to predict early mortality after cardiac surgery (Table 2). ${ }^{65-69}$ They could be an interesting tool to decide whether a patient should undergo cardiac surgery or not in case of IE. However, most of those scores were created to screen patients before elective valve replacement or coronaryarterial bypass grafting, which is obviously different from the urgent or semi-urgent surgery performed in case of IE. Then, the European guidelines also suggest using the Society of Thoracic Surgeons Endocarditis Score and the De Feo et al score, which are dedicated to surgery in IE but were evaluated only in a small number of patients. ${ }^{10,65,66}$ Additionally, none of these scores included a comprehensive geriatric assessment, whereas the European recommendations ${ }^{10}$ concede that practical indications for surgery in IE are unclear and mainly rely on the patient's clinical status and comorbidities. Only one study evaluated the potential interest of adding frailty and disability to cardiac surgery-risk scores to identify elderly patients at high risk of mortality or major morbidity, but before elective surgery excluding IE. ${ }^{70}$ In this prospective multicenter study that included 152 patients aged 70 years or over, authors showed that addition of frailty (measured 
Table 2 Characteristics of risk scores predicting mortality or morbidity after cardiac surgery

\begin{tabular}{|c|c|c|c|c|c|}
\hline & STS-PROMM ${ }^{68}$ & $\begin{array}{l}\text { Bernstein and } \\
\text { Parsonnet }^{69}\end{array}$ & Euroscore $\mathrm{II}^{67}$ & STS-IE ${ }^{65}$ & $\mathrm{De} \mathrm{Feo}^{66}$ \\
\hline Specific to IE & No & No & No & Yes & Yes \\
\hline Prediction of morbidity after surgery & Yes & No & No & Yes & No \\
\hline Number of variables included & 34 & 37 & 17 & 13 & 6 \\
\hline \multicolumn{6}{|l|}{ Variables included } \\
\hline - Age & $x$ & $x$ & $x$ & $x$ & $x$ \\
\hline - Other demographic data & $x$ & $\mathrm{x}$ & $x$ & $\mathrm{x}$ & \\
\hline - Renal failure & $\mathrm{X}$ & $x$ & $\mathrm{X}$ & $\mathrm{X}$ & $\mathrm{X}$ \\
\hline - Other extracardiac chronic diseases & $x$ & $x$ & $x$ & $x$ & \\
\hline - Previous cardiac disease & $\mathrm{X}$ & $\mathrm{x}$ & $\mathrm{X}$ & $\mathrm{X}$ & \\
\hline - Cardiac failure/cardiogenic shock at the time of surgery & $\mathrm{x}$ & $\mathrm{x}$ & $\mathrm{x}$ & $\mathrm{x}$ & $\mathrm{x}$ \\
\hline - Ventilatory support at the time of surgery & $x$ & $x$ & $x$ & $x$ & $x$ \\
\hline - Previous cardiac surgery & $\mathrm{X}$ & $\mathrm{X}$ & $\mathrm{X}$ & $\mathrm{X}$ & \\
\hline - Elective/urgent surgery & $\mathrm{X}$ & $\mathrm{X}$ & $\mathrm{X}$ & $\mathrm{X}$ & \\
\hline - Presence of IE & & $\mathrm{x}$ & & & NA \\
\hline - Positive blood culture & & & & & $\mathrm{X}$ \\
\hline - Perivalvular abcess & & & & & $x$ \\
\hline
\end{tabular}

Abbreviations: IE, infective endocarditis; STS-PROMM, Society of Thoracic Surgeons Predicted Risk of Mortality or Major Morbidity; N/A, not applicable; STS-IE, Society of Thoracic Surgeons-Infective Endocarditis.

by $5 \mathrm{~m}$ gait speed in 6 seconds) and disability (evaluated by $\geq 3$ impairments in the Nagi scale) improved model discrimination compared with Parsonnet score or the Society of Thoracic Surgeons Predicted Risk of Mortality or Major Morbidity (a different score from the Society of Thoracic Surgeons Endocarditis Score cited earlier) alone. ${ }^{68,69}$ Thus, in addition to cardiologists, infectious disease specialists, cardiac surgeons, and anesthesiologists, geriatricians should certainly play a major role to more accurately identify patients who would benefit from surgery or not in case of IE.

\section{Other components of treatment}

Comorbidities and polypharmacy are very common in elderly, and IE care should not be focused only on antibiotic administration and surgery. Of note, antiplatelet and anticoagulant agents are commonly prescribed in elderly patients. The European and American recommendations give indications on the management of antiplatelet therapy and anticoagulation during IE. ${ }^{10,11}$ Antiplatelet agents should be stopped only in the presence of major bleeding. In case of intracranial hemorrhage, any anticoagulation should be withdrawn. In the presence of a mechanical valve, unfractionated heparin should be restarted as soon as possible with close monitoring of clot tests. In ischemic stroke without hemorrhage, oral anticoagulation should be replaced by unfractionated heparin.

\section{Conclusion}

IE is becoming more common in elderly population with peculiarities in patient characteristics and bacteria involved.
This evolution raises new issues and leads clinicians to deal with specific problems in the management of this severe disease. The elders' characteristics (performance status, disability) and their impact on the treatment and the prognosis of IE may deserve great attention. Geriatricians should be more involved in this perspective. Available guidelines could be applied to fit elderly patients, but specific recommendations may certainly be necessary for the frailest ones. Therefore, improving our knowledge on specificity of IE in elderly is essential, and further studies focusing on these patients are necessary to explore those specific points.

\section{Disclosure}

The authors report no conflicts of interest in this work.

\section{References}

1. Selton-Suty C, Célard M, Le Moing V, et al. Preeminence of Staphylococcus aureus in infective endocarditis: a 1-year populationbased survey. Clin Infect Dis. 2012;54(9):1230-1239.

2. Slipczuk L, Codolosa JN, Davila CD, et al. Infective endocarditis epidemiology over five decades: a systematic review. PloS One. 2013;8(12): e82665.

3. Ramírez-Duque N, García-Cabrera E, Ivanova-Georgieva R, et al. Surgical treatment for infective endocarditis in elderly patients. J Infect. 2011;63(2):131-138.

4. Lopez J, Revilla A, Vilacosta I, et al. Age-dependent profile of leftsided infective endocarditis: a 3-center experience. Circulation. 2010; 121(7):892-897.

5. Remadi JP, Nadji G, Goissen T, Zomvuama NA, Sorel C, Tribouilloy C. Infective endocarditis in elderly patients: clinical characteristics and outcome. Eur J Cardiothorac Surg. 2009;35(1):123-129.

6. Durante-Mangoni E, Bradley S, Selton-Suty C, et al. Current features of infective endocarditis in elderly patients: results of the International Collaboration on Endocarditis Prospective Cohort Study. Arch Intern Med. 2008;168(19):2095-2103. 
7. High KP, Bradley S, Loeb M, Palmer R, Quagliarello V, Yoshikawa T. A new paradigm for clinical investigation of infectious syndromes in older adults: assessment of functional status as a risk factor and outcome measure. Clin Infect Dis. 2005;40(1):114-122.

8. Baddour LM, Epstein AE, Erickson CC, et al. Update on cardiovascular implantable electronic device infections and their management: a scientific statement from the American Heart Association. Circulation. 2010;121(3):458-477.

9. Gould FK, Denning DW, Elliott TSJ, et al. Guidelines for the diagnosis and antibiotic treatment of endocarditis in adults: a report of the Working Party of the British Society for Antimicrobial Chemotherapy. $J$ Antimicrob Chemother. 2012;67(2):269-289.

10. Habib G, Lancellotti P, Antunes MJ, et al. 2015 ESC guidelines for the management of infective endocarditis: The Task Force for the Management of Infective Endocarditis of the European Society of Cardiology (ESC). Endorsed by: European Association for Cardio-Thoracic Surgery (EACTS), the European Association of Nuclear Medicine (EANM). Eur Heart J. 2015;36(44):3075-3128.

11. Baddour LM, Wilson WR, Bayer AS, et al. Infective endocarditis in adults: diagnosis, antimicrobial therapy, and management of complications: a scientific statement for healthcare professionals from the American Heart Association. Circulation. 2015;132(15):1435-1486.

12. Delahaye F, Goulet V, Lacassin F, et al. Characteristics of infective endocarditis in France in 1991. A 1-year survey. Eur Heart J. 1995;16(3): 394-401.

13. Hoen B, Duval X. Infective endocarditis. N Engl J Med. 2013; 369(8):785.

14. Ferreiros E, Nacinovich F, Casabé JH, et al. Epidemiologic, clinical, and microbiologic profile of infective endocarditis in Argentina: a national survey. The Endocarditis Infecciosa en la República Argentina-2 (EIRA-2) Study. Am Heart J. 2006;151(2):545-552.

15. Benito N, Miró JM, de Lazzari E, et al. Health care-associated native valve endocarditis: importance of non-nosocomial acquisition. Ann Intern Med. 2009;150(9):586-594.

16. Cabell CH, Jollis JG, Peterson GE, et al. Changing patient characteristics and the effect on mortality in endocarditis. Arch Intern Med. 2002;162(1):90-94.

17. Dhawan VK. Infective endocarditis in elderly patients. Curr Infect Dis Rep. 2003;5(4):285-292.

18. Di Salvo G, Thuny F, Rosenberg V, et al. Endocarditis in the elderly: clinical, echocardiographic, and prognostic features. Eur Heart J. 2003;24(17):1576-1583

19. Gregoratos G. Infective endocarditis in the elderly: diagnosis and management. Am J Geriatr Cardiol. 2003;12(3):183-189.

20. Selton-Suty C, Hoen B, Grentzinger A, et al. Clinical and bacteriological characteristics of infective endocarditis in the elderly. Heart Br Card Soc. 1997;77(3):260-263.

21. Amat-Santos IJ, Messika-Zeitoun D, Eltchaninoff H, et al. Infective endocarditis after transcatheter aortic valve implantation: results from a large multicenter registry. Circulation. 2015;131(18):1566-1574.

22. Pericas JM, Llopis J, Cervera C, et al. Infective endocarditis in patients with an implanted transcatheter aortic valve: clinical characteristics and outcome of a new entity. $J$ Infect. 2015;70(6):565-576.

23. Verhagen DWM, Hermanides J, Korevaar JC, et al. Health-related quality of life and posttraumatic stress disorder among survivors of left-sided native valve endocarditis. Clin Infect Dis. 2009;48(11):1559-1565.

24. McMillan GJ, Hubbard RE. Frailty in older inpatients: what physicians need to know. QJM. 2012;105(11):1059-1065.

25. Kappetein AP, Head SJ, Généreux P, et al. Updated standardized endpoint definitions for transcatheter aortic valve implantation: the Valve Academic Research Consortium-2 consensus document. Eur Heart J. 2012;33(19):2403-2418.

26. Fried LP, Tangen CM, Walston J, et al. Frailty in older adults: evidence for a phenotype. J Gerontol. 2001;56(3):M146-M156.

27. Rodriguez Villarreal I, Ortega O, Hinostroza J, et al. Geriatric assessment for therapeutic decision-making regarding renal replacement in elderly patients with advanced chronic kidney disease. Nephron Clin Pract. 2014;128(1-2):73-78.
28. Faulkner CM, Cox HL, Williamson JC. Unique aspects of antimicrobial use in older adults. Clin Infect Dis. 2005;40(7):997-1004.

29. Fraisse T, Gras Aygon C, Paccalin M, et al. Aminoglycosides use in patients over 75 years old. Age Ageing. 2014;43(5):676-681.

30. Sandoe JA, Patel PA, Baig MW, West R. What is the effect of penicillin dosing interval on outcomes in streptococcal infective endocarditis? J Antimicrob Chemother. 2013;68(11):2660-2663.

31. Hughes DW, Frei CR, Maxwell PR, et al. Continuous versus intermittent infusion of oxacillin for treatment of infective endocarditis caused by methicillin-susceptible Staphylococcus aureus. Antimicrob Agents Chemother. 2009;53(5):2014-2019.

32. Cataldo MA, Tacconelli E, Grilli E, Pea F, Petrosillo N. Continuous versus intermittent infusion of vancomycin for the treatment of Grampositive infections: systematic review and meta-analysis. J Antimicrob Chemother. 2012;67(1):17-24.

33. Lee C-H, Tsai C-Y, Li C-C, Chien C-C, Liu J-W. Teicoplanin therapy for MRSA bacteraemia: a retrospective study emphasizing the importance of maintenance dosing in improving clinical outcomes. $J$ Antimicrob Chemother. 2015;70(1):257-263.

34. Fowler VG, Boucher HW, Corey GR, et al. Daptomycin versus standard therapy for bacteremia and endocarditis caused by Staphylococcus aureus. N Engl J Med. 2006;355(7):653-665.

35. Konychev A, Heep M, Moritz RKC, et al. Safety and efficacy of daptomycin as first-line treatment for complicated skin and soft tissue infections in elderly patients: an open-label, multicentre, randomized phase IIIb trial. Drugs Aging. 2013;30(10):829-836.

36. Paul M, Lador A, Grozinsky-Glasberg S, Leibovici L. Beta lactam antibiotic monotherapy versus beta lactam-aminoglycoside antibiotic combination therapy for sepsis. Cochrane Database Syst Rev. 2014;1:CD003344.

37. Fernández-Hidalgo N, Almirante $\mathrm{B}$, Gavaldà J, et al. Ampicillin plus ceftriaxone is as effective as ampicillin plus gentamicin for treating Enterococcus faecalis infective endocarditis. Clin Infect Dis. 2013;56(9): 1261-1268

38. Pericas JM, Cervera C, del Rio A, et al. Changes in the treatment of Enterococcus faecalis infective endocarditis in Spain in the last 15 years: from ampicillin plus gentamicin to ampicillin plus ceftriaxone. Clin Microbiol Infect. 2014;20(12):O1075-O1083.

39. Nicolau DP, Freeman CD, Belliveau PP, Nightingale CH, Ross JW, Quintiliani R. Experience with a once-daily aminoglycoside program administered to 2,184 adult patients. Antimicrob Agents Chemother. 1995;39(3):650-655.

40. Murry KR, McKinnon PS, Mitrzyk B, Rybak MJ. Pharmacodynamic characterization of nephrotoxicity associated with once-daily aminoglycoside. Pharmacotherapy. 1999;19(11):1252-1260.

41. Raveh D, Kopyt M, Hite Y, Rudensky B, Sonnenblick M, Yinnon AM. Risk factors for nephrotoxicity in elderly patients receiving once-daily aminoglycosides. QJM. 2002;95(5):291-297.

42. Drusano GL, Ambrose PG, Bhavnani SM, Bertino JS, Nafziger AN, Louie A. Back to the future: using aminoglycosides again and how to dose them optimally. Clin Infect Dis. 2007;45(6):753-760.

43. Foltz F, Ducher M, Rougier F, et al. Efficacy and toxicity of aminoglycoside therapy in the elderly: combined effect of both once-daily regimen and therapeutic drug monitoring. Pathol Biol (Paris). 2002;50(4): $227-232$.

44. Amodeo MR, Clulow T, Lainchbury J, et al. Outpatient intravenous treatment for infective endocarditis: safety, effectiveness and one-year outcomes. J Infect. 2009;59(6):387-393.

45. Cervera C, del Río A, García L, et al. Efficacy and safety of outpatient parenteral antibiotic therapy for infective endocarditis: a ten-year prospective study. Enfermedades Infecc Microbiol Clínica. 2011;29(8): 587-592.

46. Partridge DG, O'Brien E, Chapman ALN. Outpatient parenteral antibiotic therapy for infective endocarditis: a review of 4 years' experience at a UK centre. Postgrad Med J. 2012;88(1041): 377-381.

47. Duncan CJA, Barr DA, Ho A, Sharp E, Semple L, Seaton RA. Risk factors for failure of outpatient parenteral antibiotic therapy (OPAT) in infective endocarditis. J Antimicrob Chemother. 2013;68(7):1650-1654. 
48. Lacroix A, Revest M, Patrat-Delon S, et al. Outpatient parenteral antimicrobial therapy for infective endocarditis: a cost-effective strategy. Med Mal Infect. 2014;44(7):327-330.

49. Tice AD, Rehm SJ, Dalovisio JR, et al. Practice guidelines for outpatient parenteral antimicrobial therapy. Clin Infect Dis. 2004;38(12): 1651-1671.

50. Dardaine-Giraud V, Lamandé M, Constans T. Hypodermoclysis: benefits and indications in geriatrics. Rev Med Int. 2005;26(8):643-650.

51. Frisoli Junior A, de Paula AP, Feldman D, Nasri F. Subcutaneous hydration by hypodermoclysis. A practical and low cost treatment for elderly patients. Drugs Aging. 2000;16(4):313-319.

52. Remington R, Hultman T. Hypodermoclysis to treat dehydration: a review of the evidence. J Am Geriatr Soc. 2007;55(12):2051-2055.

53. Forestier E, Paccalin M, Roubaud-Baudron C, Fraisse T, Gavazzi G, Gaillat J. Subcutaneously administered antibiotics: a national survey of current practice from the French infectious diseases (SPILF) and geriatric medicine (SFGG) society networks. Clin Microbiol Infect. 2015; 21(4):370.

54. Borner K, Lode H, Hampel B, Pfeuffer M, Koeppe P. Comparative pharmacokinetics of ceftriaxone after subcutaneous and intravenous administration. Chemotherapy. 1985;31(4):237-245.

55. Bricaire F, Castaing JL, Pocidalo JJ, Vilde JL. Pharmacocinétique et tolérance de la ceftriaxone après injection sous-cutanée. [Pharmacokinetics and tolerance of ceftriaxone after subcutaneous administration]. Pathol Biol (Paris). 1988;36(5 Pt 2):702-705.

56. Harb G, Lebel F, Battikha J, Thackara JW. Safety and pharmacokinetics of subcutaneous ceftriaxone administered with or without recombinant human hyaluronidase (rHuPH20) versus intravenous ceftriaxone administration in adult volunteers. Curr Med Res Opin. 2010;26(2): 279-288.

57. Gauthier D, Schambach S, Crouzet J, Sirvain S, Fraisse T. Subcutaneous and intravenous ceftriaxone administration in patients more than 75 years of age. Med Mal Infect. 2014;44(6):275-280.

58. Barbot A, Venisse N, Rayeh F, Bouquet S, Debaene B, Mimoz O. Pharmacokinetics and pharmacodynamics of sequential intravenous and subcutaneous teicoplanin in critically ill patients without vasopressors. Intensive Care Med. 2003;29(9):1528-1534.
59. Carpentier E, Roméo B, El Samad Y, Geslin-Lichtenberger L, Maingourd Y, Tourneux P. Subcutaneous teicoplanin for children with infectious endocarditis. Arch Ped. 2013;20(7):775-778.

60. Leng B, Saux MC, Latrille J. Comparative pharmacokinetics of amikacin after intravenous, intramuscular and subcutaneous administration. Nouv Presse Med. 1979;8(42):3421-3425.

61. Plantin P, Mahe M, Le Noac'h E, Le Roy JP. Cutaneous necroses after subcutaneous injections of amikacin. Presse Med. 1993;22(29):1366.

62. Penso D, Delfraissy JF, Pham Van T, Dormont J. Skin necrosis following administration of subcutaneous gentamicin. Presse Med. 1984; 13(25):1575-1576.

63. Al-Omari A, Cameron DW, Lee C, Corrales-Medina VF. Oral antibiotic therapy for the treatment of infective endocarditis: a systematic review. BMC Infect Dis. 2014;14:140.

64. Lalani T, Chu VH, Park LP, Cecchi E, et al. In-hospital and 1-year mortality in patients undergoing early surgery for prosthetic valve endocarditis. JAMA Intern Med. 2013;173(16):1495-1504.

65. Gaca JG, Sheng S, Daneshmand MA, et al. Outcomes for endocarditis surgery in North America: a simplified risk scoring system. J Thorac Cardiovasc Surg. 2011;141(1):98-106.e1-2.

66. De Feo M, Cotrufo M, Carozza A, et al. The need for a specific risk prediction system in native valve infective endocarditis surgery. Scientific World Journal. 2012;2012:307571.

67. Nashef SA, Roques F, Michel P, Gauducheau E, Lemeshow S, Salamon R. European system for cardiac operative risk evaluation (EuroSCORE). Eur J Cardio-Thorac Surg. 1999;16(1):9-13.

68. Shahian DM, O'Brien SM, Filardo G, et al. The Society of Thoracic Surgeons 2008 cardiac surgery risk models: part 1 - coronary artery bypass grafting surgery. Ann Thorac Surg. 2009;88(1 Supp1):S2-S22.

69. Bernstein AD, Parsonnet V. Bedside estimation of risk as an aid for decision-making in cardiac surgery. Ann Thorac Surg. 2000;69(3): 823-828.

70. Afilalo J, Mottillo S, Eisenberg MJ, et al. Addition of frailty and disability to cardiac surgery risk scores identifies elderly patients at high risk of mortality or major morbidity. Circ Cardiovasc Qual Outcomes. 2012;5(2):222-228.
Clinical Interventions in Aging

\section{Publish your work in this journal}

Clinical Interventions in Aging is an international, peer-reviewed journal focusing on evidence-based reports on the value or lack thereof of treatments intended to prevent or delay the onset of maladaptive correlates of aging in human beings. This journal is indexed on PubMed Central, MedLine,

\section{Dovepress}

CAS, Scopus and the Elsevier Bibliographic databases. The manuscript management system is completely online and includes a very quick and fair peer-review system, which is all easy to use. Visit http://www.dovepress. com/testimonials.php to read real quotes from published authors. 